\title{
NEUROFIBROMATOSIS PRESENTING AS MACROGLOSSIA
}

\author{
BY \\ J. J. KEMPTON and C. LATTO \\ From the Paediatric Department, Royal Berkshire Hospital, Reading
}

(Received for Publication February 1, 1950)

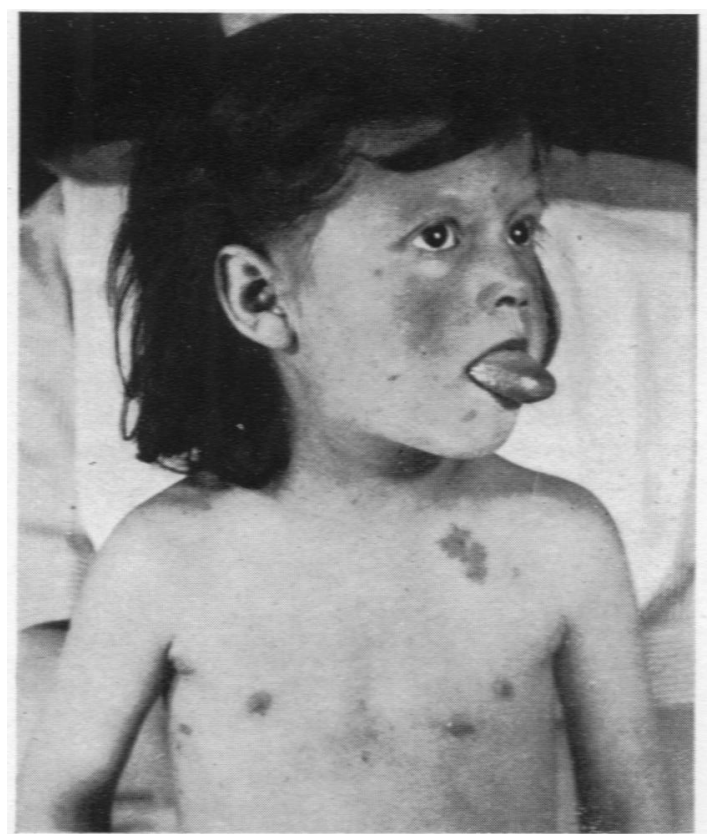

FIG. 1.-Patient showing neurofibromatosis of tongue and café-au-lait patches.

\section{Case Report}

Joyce K., aged 6, is the tenth of 12 children. The remainder of the family are healthy and there is no family history of any condition suggesting neurofibromatosis.

Birth was normal and infancy uneventful, but the mother noticed a large and slightly protruding tongue when she first saw the child a few hours after birth. She had gastro-enteritis at 6 months, but apart from this had no serious illness. She was bottle fed and no difficulties occurred, but development seemed a little slow. She did not walk until she was nearly 2, and has always been backward at school.

The tongue gradually and very slowly enlarged, and she came up to hospital in March, 1949, because it was noticed to be interfering with her speech. Pale brown patches had become apparent on the skin of her chest and shoulders at the age of four.

On examination she was a thin, puny child with a moderate kyphoscoliosis and a protruding abdomen.
There were numerous café-au-lait patches on the chest, shoulders, and abdomen, and a number of small, shotty, subcutaneous nodules could be felt in the left supraclavicular region. The tongue was much enlarged, the enlargement consisting of a diffuse tumour mass involving mainly the right side (Fig. 1).

A wedge-shaped excision of part of the tongue was carried out on June 6, 1949 . The child made an uninterrupted recovery from the operation and her speech has been much improved, though further increase in size has occurred since operation, and in addition, the supraclavicular nodules have become larger and more easily felt.

Section of the removed portion of the tongue showed the characteristic appearances of neurofibromatosis (Fig. 2).

\section{Discussion}

Neurofibromatosis is a disease of many and varied manifestations, from Treves' elephant man to small local lesions, and if all its major and minor manifestations are considered together, is not an uncommon condition. Von Recklinghausen, in his monograph published in 1882 , integrated the four main features; the skin tumours of mollascum fibrosum, the fusiform neurofibroma, the plexiform neuroma, and the café-au-lait patch. And he pointed out their common pathogenic background which he called a ' growth perversion of the foetal neuro-ectoderm.' There is usually evidence of a hereditary tendency in which sometimes not only the disease but the localization seems to be genetically determined. For example, Gardner and Frazier (1930) described familial nerve deafness due to neurofibroma, in which 38 members of one family were affected. There is commonly a certain degree of mental defect.

Before the publication of von Recklinghausen's monograph neurofibroma of the tongue associated with multiple cutaneous lesions was described in a paper published by Robert Smith in Dublin in 1849, and a detailed account of the clinical and pathological features of a case was presented to the London Pathological Society by Abbott and Shattock in 1903. Müller (1933), describing a case, suggested the name macroglossia neurofibromatosa congenita for the condition. 


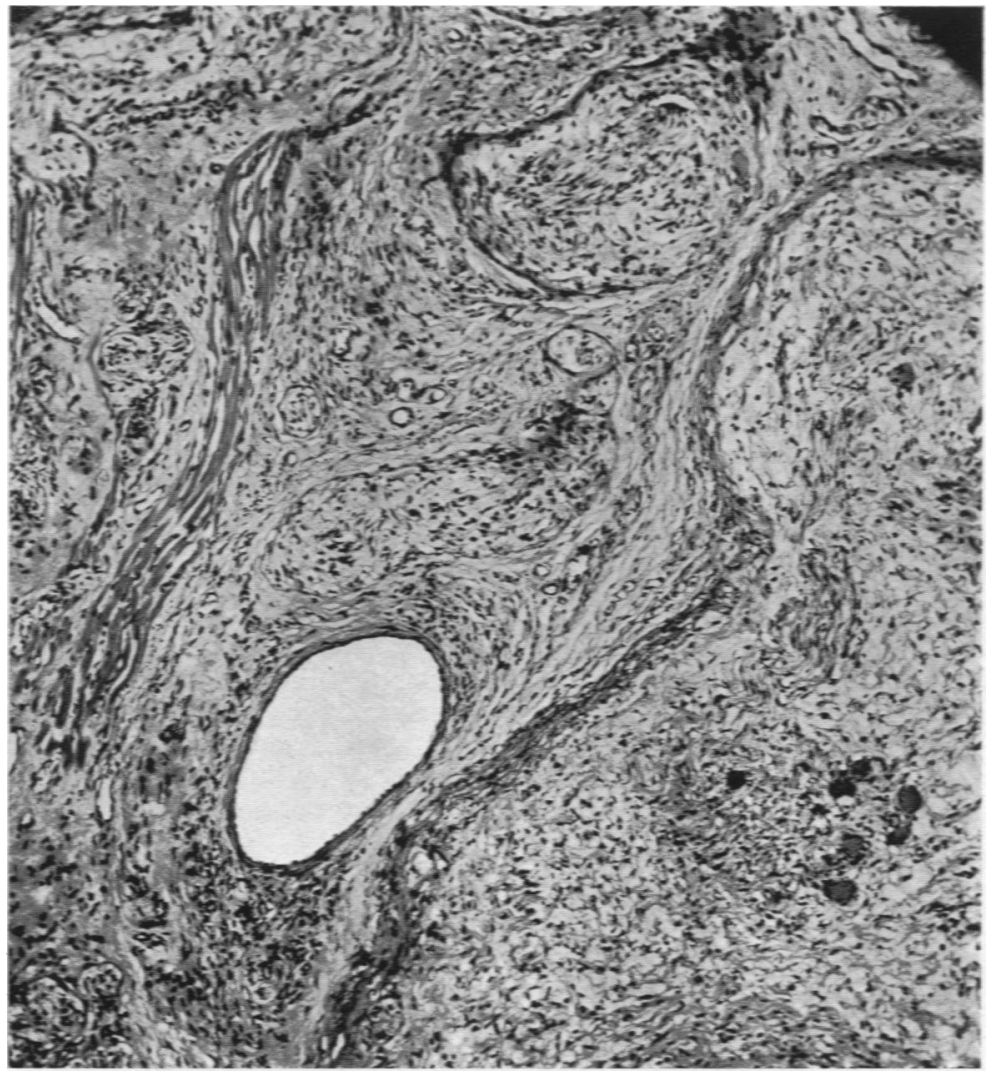

FiG. 2. Section of neurofibroma of tongue $(\times 65)$.

Neurofibromatosis presenting in infancy as macroglossia is thus a well recognized condition, but is sufficiently rare to justify this report.

Acknowledgments are due to Dr. J. Mills, pathologist to the Royal Berkshire Hospital, and to Professor Dible, in whose department at the Postgraduate Medical School the microphotograph was taken.

\section{REFERENCES}

Abbott, F. C., and Shattock, S. G. (1903). Trans. path. Soc. Lond., 54, 231.

Gardner, W. J., and Frazier, C. H. (1930). Arch. Neurol. Psychiat., Chicago, 23, 266.

Müller, H. (1933). Zbl. allg. Path. path-Amat., 57, 55.

Recklinghausen, F. D. von (1882). "Virchows Festchrift, Berlin.

Smith, R. W. (1849). 'A Treatise on Neuroma.' 